\title{
NARRATIVAS TRANSMÍDIA E TEORIA DA LITERATURA: DESAFIOS E PERSPECTIVAS
}

\author{
TRANSMEDIA STORYTELLING AND LITERARY THEORY: CHALLENGES AND \\ PERSPECTIVES
}

Márcio Roberto do Prado ${ }^{1}$

\begin{abstract}
Resumo
O presente artigo pretende apresentar uma discussão a respeito dos desafios e perspectivas referentes ao contexto da teoria da literatura por meio de uma reflexão sobre as narrativas transmídia, com exemplos de personagens tomados como elemento essencial da narrativa literária.
\end{abstract}

Palavras-chave: Literatura, Teoria da Literatura, Narrativa Transmídia, Personagem.

\begin{abstract}
This article aims at presenting a discussion about the challenges and perspectives in the context of Literary Theory through a reflection on transmedia storytelling, with examples of characters as essential part of literary narrative.
\end{abstract}

Keywords: Literature, Literary Theory, Transmedia Storytelling, Character.

Em Teoria da literatura, Vítor Manuel de Aguiar e Silva, nos anos finais da década de 1960, contribuía para que a discussão sobre a expressão que dá título ao livro ganhasse maior espaço e especificidade no universo lusófono. Tal tarefa não constituía empresa das mais simples, uma vez que basta que nos remetamos ao universo acadêmico brasileiro para verificarmos como as discussões eminentemente teóricas nem sempre obtiveram o devido espaço, em especial quando comparadas à quantidade de estudos que se limitavam a aplicar determinada perspectiva teórica a uma obra literária específica. Todavia, em cenários de modificação do objeto literário, o arcabouço teórico de que dispomos pode não ser o bastante para que sua aplicação signifique algo eficiente e pertinente. Semelhante constatação já estava presente no citado livro de Aguiar e Silva, cujo capítulo inicial "O conceito de literatura. A teoria da literatura” apresenta em seus últimos parágrafos o lúcido comentário:

\footnotetext{
1 Doutor em Estudos Literários pela Unesp/Araraquara. Professor Adjunto do Departamento de Teorias Linguísticas e Literárias - Universidade Estadual de Maringá. E-mail: metatron58@yahoo.com.bremrprado@uem.br
} 


\begin{abstract}
A teoria da literatura [...] deve evitar uma tentação que arruinou e desacreditou a poética e a retórica dos séculos XVI, XVII e XVIII: a tentação de estabelecer regras que pretendam vincular o criador literário. Perante a diversidade histórica do fenómeno literário, é absurdo emitir regras dogmáticas que pretendam assumir função normativa e judicativa: intentar excluir, por exemplo, a inteligência da criação poética e estabelecer esta exclusão como um princípio normativo, desconhecendo assim tanto Boileau como Paul Valéry, T. S. Eliot como Ricardo Reis. Não se trata de elaborar regras ou normas, mas sim de compreender, de organizar conceptualmente um determinado conhecimento acerca do fenómeno estético-literário.
\end{abstract}

Este conhecimento, em vez de prejudicar, vem intensificar a fruição estética e revelar mais plenamente uma das mais esplendorosas experiências e aventuras humanas, porque, como afirma Hegel, "aquilo que se sabe é bem superior àquilo que não se sabe”. (AGUIAR E SILVA, 1969, p. 57)

A lembrança de Aguiar e Silva não se dá, aqui, sem motivo. Um retorno à década de 1960 pode nos fazer perceber, com mais propriedade, como determinados desafios e perspectivas dos tempos atuais já se encontravam, ao menos em potência, desde um período muito anterior (anterior até mesmo aos anos 1960, por sinal). Porém, a urgência promovida por novas manifestações no âmbito da arte literária - e em campos artísticos limítrofes intensifica nossa percepção de que, por exemplo, o instrumental oferecido pela teoria da literatura não seja capaz de dar conta das demandas que se apresentam, sobretudo a partir da dinâmica estabelecida entre a literatura, os recursos tecnológicos e os meios de comunicação, em especial aqueles relacionados à internet.

Esse é o caso das narrativas transmídia. Quando pensamos no contexto dessas narrativas, o que normalmente surge de modo imperioso são as implicações do ponto de vista comunicacional ou os reflexos (apenas para evitarmos a velha - e equivocada - metáfora do “impacto”, tal como adverte Pierre Lévy [1999, p. 21]) dessa prática artística em nossa maneira de ler. Sempre destacamos como essas narrativas reiteram a dimensão colaborativa, atualizando uma verdadeira inteligência coletiva em termos que são efetivamente convergenciais. Em seguida, percebemos como isso traz implicações diretas na maneira como, por exemplo, os alunos digitalmente nativos leem, o que exige do professor cuidado e capacidade para ter em mente essa particularidade, bem como para se manter atualizado e apto a explorar as potencialidades que se abrem pelos recursos tecnológicos em geral, com destaque para o computador e a internet. Sem dúvida isso é importante e merece o destaque que sempre recebe; todavia, algumas frentes de reflexão nem sempre ganham a atenção necessária e, quando isso ocorre, suas implicações podem deixar de ser problematizadas como seria devido. É o caso de algumas questões teóricas, mais especificamente do ponto de vista 
da teoria da narrativa, que, sob a égide e as demandas das narrativas transmídia, abrem-se a novas perspectivas tão instigantes quanto propensas a gerar dúvidas, receios e equívocos.

Em função das limitações de recorte da discussão aqui proposta, enfoquemos uma categoria narrativa em especial para que possamos ilustrar a reflexão: a personagem. Elemento fundamental para a constituição do gênero épico, a personagem permite-nos vislumbrar de modo paradigmático as implicações teóricas mencionadas. Basta que pensemos em termos de caracterização, contrastando a personagem na literatura tradicional à personagem que emerge a partir da realidade transmidiática. Se retomarmos um texto clássico em nosso universo intelectual brasileiro, “A personagem do romance”, de autoria do mestre Antonio Candido, poderíamos pensar na personagem de um romance, por exemplo, a partir dos seguintes termos:

Os elementos que um romancista escolhe para apresentar a personagem, física e espiritualmente, são por força indicativos. Que coisa sabemos de Capitu, além dos “olhos de ressaca”, dos cabelos, de “certo ar de cigana, oblíqua e dissimulada”? O resto decorre da sua inserção nas diversas partes de Dom Casmurro; e embora não possamos ter a imagem nítida da sua fisionomia, temos uma intuição profunda do seu modo-de-ser, - pois o autor convencionalizou bem os elementos, organizando-os de maneira adequada. Por isso, a despeito do caráter fragmentário dos traços constitutivos, ela existe, com maior integridade e nitidez do que um ser vivo. A composição estabelecida atua como uma espécie de destino, que determina e sobrevoa, na sua totalidade, a vida de um ser; os contextos adequados asseguram o traçado convincente da personagem, enquanto os nexos frouxos a comprometem, reduzindo-a à inexpressividade dos fragmentos. (CANDIDO, 2002, p. 78-9)

A passagem, oriunda do livro A personagem de ficção, encontra um ponto de comparação interessante em outro texto do mesmo volume, “A personagem cinematográfica”, de autoria de Paulo Emílio Salles Gomes. Ao tratar da personagem no âmbito do cinema, apesar de iniciar seu texto apontando para o diálogo que o próprio cinema estabelece com a literatura e o teatro, o autor busca destacar os meios de caracterização da personagem da seguinte maneira:

O que ficou dito a respeito das diferentes maneiras de enfocar a personagem e o parentesco flagrante entre romance e cinema que daí decorre, não nos deve levar a nenhum delírio de identificação. A personagem de romance afinal é feita exclusivamente de palavras escritas, e já vimos que mesmo casos minoritários e extremos em que a palavra falada no cinema tem papel preponderante na constituição de uma personagem, a cristalização definitiva desta fica condicionada a um contexto visual. Nos filmes, por sua vez, e em regra generalíssima, as personagens são encarnadas em pessoas. Essa circunstância retira do cinema, arte de presenças excessivas, a liberdade fluida com que o romance comunica suas personagens aos leitores. Um inquérito limitado e fortuito foi suficiente para me levar à conclusão de que o leitor médio moderno visualiza Carlos da Maia sem barbas; entretanto, no texto de Eça de Queirós, o herói não só as possui, como elas 
têm função dramática pelo menos numa cena aflitiva com a Condessa de Gouvarinho. Esse exemplo de deformação indica a margem de liberdade de que dispomos diante de uma personagem que emana apenas de palavras. A Capitu de uma fita de cinema nunca seria essencialmente olhos e cabelos, e nos imporia necessariamente tudo o mais, inclusive pés e cotovelos. Essa definição física completa imposta pelo cinema reduz a quase nada a liberdade do espectador nesse terreno. (GOMES, 2002, p. 111)

Há uma razão para contrapor dois textos de uma obra que, embora ainda mantenha seu valor em pleno século XXI, não poderia ser considerada o dernier cri em termos de discussão teórica sobre a categoria narrativa em questão: eles representam um momento de relativa segurança em termos de assentamento teórico e que, sobretudo, permitia a segmentação de $A$ personagem de ficção em capítulos que não apenas distinguiam a personagem do romance daquela do cinema, mas até mesmo propunha distinção mais problemática entre a personagem na literatura (caso do romance) e a do teatro. É importante frisar esse aspecto pois, no caso do teatro, a percepção pós-aristotélica de um "gênero dramático” traz uma implicação teórica e procedimental que alinha o gênero ao universo mais amplo da literatura em sentido lato, ainda que consideremos a particularidade do espetáculo como um caso à parte.

Obviamente, desde a época da primeira publicação de A personagem de ficção, livro surgido a partir de um boletim publicado originalmente na mesma década já mencionada, em 1964, eram encontradas abordagens que relativizavam os limites e mesmo obras nas quais esses limites tornavam-se difusos (o próprio texto de Paulo Emílio Salles Gomes abre-se destacando esse aspecto), mas, trabalhando em prol da separação, havia uma compartimentação mais assentada (ao menos em termos de percepção) no tocante às obras que serviam de base para essa separação oriunda de um esforço teórico - e, por conseguinte, crítico - de compreensão de uma categoria como a personagem. Apenas para ficarmos no contexto brasileiro, um romance como Memórias sentimentais de João Miramar, de Oswald de Andrade, poderia acusar a influência e o diálogo com o cinema, mas não deixava maiores dúvidas quanto à sua filiação literária, o que nos permitiu, através dos anos, uma abordagem do romance oswaldiano, levando em conta apenas o instrumental da teoria da literatura, apesar de suas provocações no tocante aos gêneros literários. Porém, com o advento em especial da internet e o desenvolvimento dos meios de comunicação em geral trabalhando para uma constante e progressiva conectividade em escala planetária, limites e fronteiras, antes razoavelmente bem estabelecidos, começam a ruir e abrem espaço para o surgimento de novas manifestações artístico-culturais que apresentam desafios específicos. É o caso de propostas como a da complexa obra conhecida como Matrix, cujas figuras de proa são os irmãos Wachowski. Após o sucesso de um primeiro filme em 1999, os Wachowski elaboraram 
e colocaram em prática um ambicioso projeto de trabalho não apenas com uma cinessérie - e portanto, toda uma franquia - de sucesso, inclusive financeiro: eles se lançaram na confecção de um verdadeiro “universo Matrix”, no qual a ideia de obra não mais estava atrelada a um filme - três filmes, no caso - capaz de gerar subprodutos rentáveis, sendo, antes, o resultado da composição orgânica de um complexo de manifestações artísticas que, separadamente, poderiam ser enfocadas a partir de um recorte específico. Deste modo, os filmes aliaram-se a animações, quadrinhos, games, fóruns de discussão na internet, dentre outras formas de abordagem e disseminação do fenômeno Matrix, mas sem uma hierarquia oficial entre os elementos, embora a percepção dos filmes como a "matriz da Matrix" seja algo que se insinue. Henry Jenkins argutamente percebe a dimensão do cenário, ao afirmar, no capítulo de seu clássico Cultura da convergência, dedicado à análise de Matrix, "Em busca do unicórnio de origami”:

\begin{abstract}
Matrix é entretenimento para a era da convergência, integrando múltiplos textos para criar uma narrativa tão ampla que não pode ser contida em uma única mídia. Os irmãos Wachowski jogaram o jogo transmídia muito bem, exibindo primeiro o filme original, para estimular o interesse, oferecendo alguns quadrinhos na web para sustentar a fome de informações dos fãs mais exaltados, publicando o anime antes do segundo filme, lançando o game para computador junto com o filme, para surfar na onda da publicidade, levando o ciclo todo a uma conclusão com Matrix Revolutions, e então transferindo toda a mitologia pra um jogo on-line para múltiplos jogadores em massa (MMOG - Massively Multiplayer Online Game). Cada passo fundado no que veio antes, enquanto novos pontos de acesso eram oferecidos.
\end{abstract}

Matrix também é entretenimento para a era da inteligência coletiva. Pierre Lévy especula sobre que tipo de obras estéticas responderia às exigências das culturas do conhecimento. Primeiro, ele sugere que a "distinção entre autores e leitores, produtores e espectadores, criadores e intérpretes irá se dissolver" e formar um "circuito" (não exatamente uma matriz) de expressão, com cada participante trabalhando para "sustentar a atividade" dos outros. A obra de arte será o que Lévy chama de "atrator cultural", unida, criando uma base comum entre as diversas comunidades; podemos também definir a obra de arte como um ativador cultural, impulsionando sua decifração, especulação e elaboração. O desafio, diz ele, é criar obras com profundidade suficiente para justificar um empreendimento em tão larga escala: "Nosso primeiro objetivo deveria ser evitar que a obra seja concluída muito rápido". Matrix funciona claramente tanto como um atrator cultural quanto um ativador cultural. Os consumidores mais envolvidos vão atrás de dados em múltiplos meios, esquadrinhando cada texto à procura de revelações de seu universo. Keanu Reeves explicou aos leitores da TV Guide: "Como o público vai interpretar Revolutions depende de quanta energia irá colocar no filme. O roteiro está cheio de becos sem saída e passagens secretas". Os espectadores aproveitam ainda mais a experiência quando comparam observações e compartilham recursos do que quando tentam seguir sozinhos. (JENKINS, 2009, p. 137-8)

A passagem é emblemática, e ilustra com propriedade o universo que se descortina a partir de uma narrativa transmídia, em especial quando a percebemos como tal e a abordamos 
apropriadamente, inclusive por meio das práticas de interação que uma narrativa dessa natureza pressupõe. Porém, aqui, começamos a perceber um certo ruído que a empolgação e o deslumbramento proporcionados pelas possibilidades não podem nos impedir de perceber. $\mathrm{O}$ ruído insinua-se nos levando a notar que, se uma personagem do universo de Matrix pode - e deve - ser plenamente apreendida por meio também dos quadrinhos e das animações, apenas para ficarmos com dois casos, isso implicaria, no mínimo, o convívio de poéticas diferentes, com procedimentos de invenção igualmente diferentes e que exigem, por seu turno, uma perspectiva teórica e um enfoque crítico também particularizados.

Tal cenário, se considerarmos o exercício da análise científica “profissional” (em suma, aquela que desenvolvemos nas universidades), implica a formação de um intelectual diferenciado, capaz não apenas de transitar pelas diferentes manifestações artísticas, mas capaz também de dominar aspectos teóricos e críticos que lhe permitam abordar esse novo objeto sem qualquer laivo de diletantismo. Em tempos de hiperespecialização de nichos acadêmicos, tal perspectiva soa como "assustadoramente" generalista e, tendo em vista o desafio que se apresenta e a quantidade de informação gerada em progressão geométrica, não seria preciso ironia ou malícia para perceber que, realmente, encontramo-nos diante de um impasse: como articular um discurso científico em tais termos sem que sejamos naturalmente atraídos pelos infinitos pontos de uma dispersão poderosa?

O cenário é desafiador, mas ainda não foi destacado um aspecto mais intrigante que pode ser percebido a partir do mesmo exemplo de Matrix. Se o convívio e o choque de poéticas nos levam ao impasse de uma “especialização generalista”, o que dizer, então, da realidade dos games ou dos fóruns de discussão? Ao atrelar nossa noção de narrativa também a uma prática como a de um jogo, inserimos na constituição das categorias narrativas um elemento que não pode ser apreendido de modo efetivo. Não se trata apenas de uma experiência particular de "zerar” o game em questão, mas, em última instância, a soma das diversas possibilidades de experiência do jogo em termos individuais ("zerar” pela segunda vez leva a uma performance diferenciada) e das diversas possibilidades de experiência dos diversos atores que se inserem no contexto complexo do universo transmidiático, inserindo na mistura os diversos jogadores, com suas performances particularizadas. À primeira vista, pode parecer um excesso tal expansão mesmo em um contexto tão conectado e interpenetrado como o nosso, mas basta que entremos em uma página de um “detonado” qualquer de um jogo qualquer, levando em conta os diversos comentários, para percebermos como essa dimensão abrangente é presente e pertinente. Nesse ponto, é interessante destacar os fóruns de discussão mencionados. Nos fóruns, quando realizam plenamente sua função, especulações 
dão margem a debates que podem ser, a despeito do preconceito daqueles que são estranhos a tal fenômeno, profundos e provocativos, apontando para caminhos que, não seria absurdo imaginar, influenciam os produtores do complexo artístico que está na origem de tais discussões, em uma retroalimentação discursiva que, se a estendermos às discussões promovidas com embasamento teórico-crítico, implica uma retroalimentação também nessa esfera, abrindo espaço para um novo impasse do ponto de vista científico: como poderia o cientista abordar seu objeto sabendo que seu bisturi analítico, ao tocar esse objeto, modifica-o de modo efetivo? Como poderia esse cientista manter sua perspectiva de desvelamento se cada tentativa de retirada do véu muda a face que ele escondia? São problemas que a narrativa transmídia nos apresenta e dos quais não podemos fugir.

Para ilustrar o fato, retornemos a nosso recorte inicial e enfoquemos a personagem enquanto categoria da narrativa. Quando pensamos em um universo expandido, como aquele que é gerado a partir dos filmes de Star Wars, temos uma figura dominante em termos de “autoridade autoral” no caso de George Lucas, e qualquer personagem que seja trabalhado em outra mídia, por mais que possa receber a contribuição criativa daquele que a trabalhe, deve respeitar um cânone e, em última instância, trabalhar de modo reiterativo em termos de caracterização dessa personagem - ainda que por meio de poéticas diferentes. Em uma autêntica narrativa transmídia, com a abertura real à contribuição de outros criadores, temos algo diferente. Quando os irmãos Wachowski procuraram nomes como Paul Chadwick, Dave Gibbons ou Neil Gaiman para contribuírem com os quadrinhos, eles não pretendiam impedir que o potencial de inovação desses artistas fosse plenamente realizado. Desse modo, temos um cenário mais complexo do que aquele que encontramos nos universos expandidos. Ficando ainda com o exemplo da personagem, temos uma dimensão reiterativa que surge naturalmente da prática convergencial, mas ela convive em harmonia tensa com uma dimensão contrastiva que é o fruto da criatividade dos artistas que produzem sua arte em uma estrutura a princípio não hierarquizada. Ao mesmo tempo em que a personagem Morpheus de Chadwick reitera a personagem encarnada por Laurence Fishburne nos filmes, sua inserção na história em quadrinhos “A história do moleiro” (CHADWICK, 2009, p. 119-30) cria-lhe um background particular e interfere em sua percepção em termos de motivações e coerência actancial, modificando, ainda que de modo sutil, sua caracterização. Novamente cabem algumas perguntas: é possível abordar uma personagem em semelhante contexto tendo como ferramentas os elementos da teoria da narrativa literária? Se não, como articular as diversas necessidades teóricas ou críticas que dela advêm sem cair em um diletantismo perigoso? 
Responder às perguntas é algo de que realmente não podemos escapar, pois até mesmo os territórios mais seguros da "literatura propriamente dita” são afetados por essa dinâmica comunicacional. Tomemos por base uma das personagens mais famosas dos últimos tempos, Harry Potter, que surge como o bruxinho do primeiro romance da série, Harry Potter and the philosopher's stone (Harry Potter and the sorcerer's stone na edição estadunidense) em 1997. Diante do sucesso da série, não houve espanto quando a gigante Warner comprou os direitos para a adaptação cinematográfica. De 2001 a 2011, viu-se a consolidação de um dos maiores sucessos da história do cinema, com o ator Daniel Radcliffe no papel principal. Embora não tenhamos aqui um caso de autêntica narrativa transmídia, o fato de os livros e a cinessérie de Harry Potter inserirem-se em um universo propício para a prática transmidiática, somado ao fato de três livros da série terem sido publicados após o surgimento dos filmes, bem como ao fato de os fãs em geral, leitores-espectadores, serem muitas vezes participantes ativos de contextos transmidiáticos, gera um fenômeno curioso, no qual, a despeito do projeto, livros e filmes se interpenetram, gerando uma caracterização complexa, do ponto de vista narrativo, da personagem.

Mesmo aqui a problematização teórica está presente, pois, ao fornecer um rosto específico para o protagonista - no caso, o próprio Daniel Radcliffe - o filme direciona a caracterização que no livro era produzida em termos de poética literária. Logo no primeiro capítulo do livro ("The boy who lived”) encontramos elementos que comporão de modo icônico a personagem:

Dumbledore and Professor McGonagall bent forward over the bundle of blankets. Inside, just visible, was a baby boy, fast asleep. Under a tuft of jet-black hair over his forehead they could see a curiously shaped cut, like a bolt of lightning.

"Is that where -?" whispered Professor McGonagall.

"Yes," said Dumbledore. "He'll have that scar forever. (ROWLING, 1999, p. 15)

Na constatação da particularidade física, surge um elemento de caracterização da personagem poderoso, uma vez que antecipa outras particularidades que serão elaboradas $a$ posteriori com relação ao protagonista, bem como aponta para um fato que, na economia do enredo, direciona-se para o passado, em uma tessitura complexa do que Harry Potter (a personagem), circunscrito pela série romanesca, é, será e o porquê. Levado para o cinema, Harry Potter reitera elementos importantes do ponto de vista da identificação física, como os óculos ou a famosa cicatriz em forma de raio. Contudo, ao articular essa caracterização com outra poética, como é o caso da poética cinematográfica, elementos típicos desse novo 
universo, como a interpretação do ator, entram nessa caracterização, modificando até mesmo de modo retroativo a personagem enquanto categoria da narrativa. A personagem no cinema projeta-se, plenamente realizada em termos visuais, na personagem do romance, a despeito de isso não ter sido intencional - ou ao menos francamente premeditado - quando a série romanesca se inicia. Novamente, aqui, vale reforçar que a série de romances ainda não havia sido finalizada quando do surgimento do primeiro filme da cinessérie. Diante da dimensão coletiva representada pelos fãs - com suas próprias contribuições por meio, dentre outras coisas, de fanfictions, por sinal - não podemos supor que J. K. Rowling estivesse imune à influência desse diálogo. Além disso, o não menos importante aspecto financeiro representado por uma franquia extremamente lucrativa pode influenciar de modo direto rumos, opções e soluções na própria estrutura romanesca.

Mantendo a reiteração das perguntas apresentadas nesta discussão, novamente repetimos a indagação: pode um especialista que, do ponto de vista da narrativa, utilize um instrumental teórico-crítico literário, dar conta dos aspectos específicos da narrativa transmídia - bem como dos aspectos nascidos a partir dela - que surgem como incontornáveis? Como a narratologia em sentido lato pode abordar de modo eficiente uma categoria como a personagem sem negligenciar, por exemplo, a arborescência de caracterização pela qual essa categoria passa a partir das diversas leituras-escrituras que são percebidas em filmes, quadrinhos, games, fanfictions e afins? A solução cada vez mais passa pelo surgimento de novas áreas do saber, com suas formas de abordagem próprias e com suas propostas teóricas e críticas. Ou, ao menos, por uma refundação do estudioso e do especialista em literatura, que passaria a enfrentar, do ponto de vista da narrativa, a necessidade de plasmar um novo instrumental teórico, capaz de fugir do lugar-comum que faz de todos os problemas um prego uma vez que se dispõe apenas de um martelo.

Não é fácil, até mesmo em função de toda uma bagagem narratológica (sempre pensada aqui em sentido lato) que, assentada na tradição e pela tradição, formou gerações, inclusive daqueles que, hoje, tentam fazer frente a questões como as suscitadas pela narrativa transmídia. Trata-se, portanto, de uma refundação em termos identitários que sempre será um desafio para qualquer sujeito que pretenda se manter como sujeito; da falta de chão, surge o receio, muitas vezes amparado em uma honesta preocupação com limites e com o rigor. Mas as demandas se apresentam em toda sua urgência, e não é possível negligenciá-las. Além disso, a recompensa que se anuncia abre espaço para avanços em outras frentes além das especificamente artísticas ou literárias. Em livro intitulado $O$ futuro da internet: em direção a 
uma ciberdemocracia planetária, André Lemos e Pierre Lévy fecham o capítulo intitulado “A mutação das mídias” com uma reflexão interessante:

\begin{abstract}
Mesmo se mantivermos certo distanciamento em face dessa inflação da "esfera pública" (uma esfera pública fractal, rizomática, que se refrata em milhões de ângulos diferentes nos sítios e nas comunidades virtuais do ciberespaço), é forçoso constatar que ela parece irreversível. A evolução contemporânea da liberdade de expressão no ciberespaço, assim como a explosão quantitativa e qualitativa da web e de suas diversas ferramentas interativas, participativas e colaborativas, parece caminhar para uma situação onde todas as instituições, empresas, grupos, equipes e indivíduos tornar-se-ão sua própria mídia e animarão a comunidade virtual que corresponde à sua zona de influência social. As relações sociais, econômicas, culturais se alinharão em relações de intermedialidade, de trocas de hiperlinks e de recortes de comunidades virtuais. Assim, a mutação das mídias concerne de fato, potencialmente, a todos os atores sociais, que se tornam, de alguma forma, mais autônomos. E isso tem implicações políticas profundas. Sempre que podemos produzir com voz livre (liberação do polo da emissão), nos organizar, conectar e produzir coisas coletivamente (o princípio de conexão), iremos, com certeza, produzir reconfigurações nas instituições culturais, no fazer político, no espaço público, na democracia. (LEMOS, LÉVY, 2010, p. 82-3)
\end{abstract}

Ao menos dois aspectos merecem destaque mais intenso. Primeiramente, a ideia de "se tornar sua própria mídia”, que aponta para uma plena vivência e uma plena agência do processo comunicacional dinâmico como um todo e que traz como subproduto de sua aplicação no contexto literário a possibilidade de aproximar as atividades de leitura (especializadas ou não) e de escritura, levando a uma total libertação de qualquer ranço passivo ou excludente, permitindo a experiência da obra de arte em sua organicidade. O outro aspecto diz respeito à dimensão democratizante que surge, de início, como promessa. Mas, ao se perceber que o aparente impasse diante do qual os estudos literários se encontram na verdade se traduz como necessidade de invenção e postura ativa, percebe-se também que não se trata de criar novas amarras para limitar ainda mais o pensamento. O que se oferece a olhos vistos é justamente o contrário: um convite à libertação inerente ao território novo explorado com equipamentos igualmente inauditos, que geram medo na mesma proporção em que estimulam.

Aqui, cabe ainda uma breve pausa reflexiva para reforçar uma consequência que se faria notar em caso de simples aceitação acrítica de semelhante dinâmica, com reflexos diretos e evidentes no âmbito da própria teoria da literatura: ao se abrir espaço para essa dimensão (cri)ativa que afeta o próprio exercício analítico e judicativo - além, obviamente, do teórico -, não corremos o risco de aproximar a crítica e a teoria da literatura da própria literatura como arte a ponto de gerar uma perigosa indistinção entre arte e ciência, com danos conceituais para ambas as frentes? Antoine Compagnon, em seu $O$ demônio da teoria, já 
destacava tal risco. Na conclusão do livro, "A aventura teórica" (COMPAGNON, 2006, p. 257-62), Compagnon destaca como as fronteiras entre teoria e ficção podem ser fluidas, com problematizações evidentes, e aponta de modo pertinente:

\begin{abstract}
Assim, a teoria literária parece, em muitos aspectos, uma ficção. Não se crê nela positivamente, mas negativamente, como na ilusão poética [...]. De repente, reprovar-me-ão talvez de levá-la excessivamente a sério e de interpretá-la literalmente demais. [...] Estaria quase de acordo com todos esses pontos: a teoria é como a ciência-ficção, e é a ficção que nos agrada, mas, pelo menos por um tempo, ela ambicionou tornar-se uma ciência. Gostaria de lê-la como a um romance [...]. Entretanto, disposto a ler romances, como não preferir aqueles que não preciso fingir que são romances? A ambição teórica merece mais que essa defesa leviana que cede ao essencial; ela deve ser levada a sério e avaliada segundo seu projeto. (COMPAGNON, 2006, p. 258-259)
\end{abstract}

É sempre importante destacar esse aspecto final da passagem de Compagnon. A despeito de qualquer proximidade que possamos estabelecer entre o campo teórico-crítico e o artístico, é fundamental ter em mente que a teoria da literatura possui um projeto, por vezes de discernimento difícil, mas, ainda assim, um projeto, acompanhado de um estatuto científico e filosófico que nos permite separar essa teoria de qualquer manifestação artística em termos conceituais. Se os limites se tornam imprecisos, isso se dá pela constatação já reiterada de modo específico ao menos desde o assentamento efetivo da teoria da literatura no primeiro romantismo alemão por meio de constatações como a de Friedrich Schlegel, segundo a qual “poesia só pode ser criticada por poesia” (SCHLEGEL, 1994, p. 91). Uma vez que a afirmação não se limitava ao contexto da passagem do século XVIII para o XIX, sendo extensiva à literatura como um todo, o que temos é a necessidade de se responder à provocação poética (pensada aqui em termos de poíesis, sem que se possa abrir espaço para qualquer confusão com a esfera do poema, do lírico) por meio de um discurso que seja ele próprio fundado no âmago dessa poíesis. Assim, em consonância com a chamada às armas de Schlegel, a tendência a uma apropriação da dimensão criativa que se nota hoje como recorrente no contexto cibercultural mostra-se como mais uma das transformações pelas quais o discurso humano sobre a arte passou, sempre em busca de uma poíesis ativa em oposição discursiva, frise-se - a uma mímesis passiva. Em outros termos, a alethea idealizada, o desvelamento de uma verdade última da arte em geral e da literatura em particular, perde espaço para um discurso teórico-crítico que se encontra em devir tanto quanto a esfera artística sobre a qual ele se debruça. Entretanto, a proximidade é procedimental, e não conceitual. Ambos, teoria e literatura, no caso de nosso recorte, compartilham um modus operandi, embora mantenham sua identidade e especificidade. 
Conforme já foi afirmado e reafirmado em nossa discussão, tal cenário leva-nos a uma posição a princípio desconfortável na qual nos encontramos diante de uma encruzilhada. Em uma das vias, aproximamos a literatura de tantas outras frentes artísticas e não-artísticas que corremos o risco de descaracterizá-la a tal ponto que ela talvez deixe de ser literatura em sentido estrito, de modo que acondicionamos sob a segurança do termo um outro objeto que perderia seu direito ao próprio nome, gerando, por fim, o risco de uma inadequação essencial entre o instrumental da teoria da literatura e aquilo que se oferece. $\mathrm{Na}$ outra via, aceitamos as diversas possibilidades como frentes autônomas (no caso das diversas linguagens artísticas que são percebidas em fenômenos como o das narrativas transmídia) e, assim, percebemos que devemos nos questionar se o estudioso tradicional da literatura pode dar conta de tantas frentes que não são, em essência, literatura, exigindo ferramentas teórico-críticas específicas e, dessa maneira, exigindo um novo tipo de intelectual: um paradoxal especialista-generalista, capaz de dar conta das diversas linguagens e poéticas envolvidas em seus focos de interesse. Talvez a resposta mais precisa articule as duas perspectivas: um novo intelectual, com um novo arsenal teórico-crítico, capaz de dar conta do novo desafio sem perder de vista a esfera, a dimensão e a natureza daquilo que é especificamente literário. Nesse caso e nesse ponto, caberia a pergunta muito pertinente sobre o motivo de se discutir algo aparentemente tão alheio ao universo literário em termos científicos, filosóficos e artísticos em um texto que se pretende uma discussão no âmbito da literatura. A resposta e a justificativa encontram-se no fato de que não podemos ainda descartar a possibilidade de que o novo cenário, com seus objetos de atenção tais como as narrativas transmídia, seja justamente o futuro, ou uma possibilidade de futuro, de uma literatura em constante devir. Afinal, se aceitamos os ditirambos de Dionísio como uma das sementes das quais se desenvolveu a árvore da literatura, porque não poderíamos encarar uma obra como o complexo representado por Matrix como um de seus frutos, a despeito de seu sabor ainda exageradamente exquis? Se nessa nova encruzilhada dos estudos da literatura encontramos essa perspectiva, então, na verdade, voltamos como sempre a um modus operandi recorrente da arte, com a desterritorialização essencial por meio da qual essa arte sempre foge ao esgotamento discursivo, ainda que especializado, técnico e institucionalizado. E isso é bom, pois traz em seu bojo a certeza de que ainda temos algo a dizer sobre as velhas questões que, na segunda década do século XXI, apontam para o futuro e nos levam a acompanhá-las rumo ao amanhã.

\section{Referências}


AGUIAR E SILVA, Vítor Manuel. Teoria da Literatura. Coimbra: Almedina, 1969.

CANDIDO, Antonio, et al. A personagem de ficção. São Paulo: Perspectiva, 2002.

. “A personagem do romance”. In: CANDIDO, Antonio, et al. A personagem de ficção. São Paulo: Perspectiva, 2002. p. 51-80.

GOMES, Paulo Emílio Salles Gomes. “A personagem cinematográfica”. In: CANDIDO, Antonio, et al. A personagem de ficção. São Paulo: Perspectiva, 2002. p. 103-119.

CHADWICK, Paul. "A história do moleiro”. In: WACHOWSKI, Andy; et al. The Matrix Comics. Tradução e adaptação de Fábio Fernandes/FD. São Paulo: Panini, 2009. p. 119-30.

COMPAGNON, Antoine. O demônio da teoria: literatura e senso comum. Tradução de Cleonice Paes Barreto Mourão e Consuelo Fortes Santiago. Belo Horizonte: Editora da UFMG, 2006.

JENKINS, Henry. Cultura da convergência. Tradução de Susana Alexandria. São Paulo: Aleph, 2009.

LEMOS, André; LÉVY, Pierre. O futuro da internet: em direção a uma ciberdemocracia planetária. São Paulo: Paulus, 2010.

LÉVY, Pierre. Cibercultura. Tradução de Carlos Irineu da Costa. São Paulo: Editora 34, 1999.

ROWLING, Joanne Katheleen. Harry Potter and the sorcerer's stone. New York: Scholastic Inc., 1999.

SCHLEGEL, Friedrich. Conversa sobre a poesia e outros fragmentos. Tradução de VictorPierre Stirnimann. São Paulo: Iluminuras, 1994. (Biblioteca Pólen)

WACHOWSKI, Andy; et al. The Matrix Comics. Tradução e adaptação de Fábio Fernandes/FD. São Paulo: Panini, 2009. 